\title{
Polymorphisms of Methylene Tetrahydrofolate Reductase (MTHFRC677T and A1298C) and Probable Depression in Postpartum Period in South Indian Women
}

\section{Pooja Dhiman}

JIPMER

Raji Pillai

JIPMER

Anand Babu Wilson

JIPMER

Nancy Premkumar

JIPMER

Balaji Bharadwaj

JIPMER

Veena $P$

JIPMER

Soundravally Rajendiran ( $\square$ soundy27@gmail.com )

JIPMER

Primary research

Keywords: Depression, postpartum, folate

Posted Date: March 9th, 2021

DOl: https://doi.org/10.21203/rs.3.rs-212401/v1

License: (c) (1) This work is licensed under a Creative Commons Attribution 4.0 International License. Read Full License 


\section{Abstract}

Background: Two common variants of Methylene tetrahydrofolate reductase (MTHFR) are C677T and A1298C, which have been associated with general depression. Main objective of the study was to explore how these functional polymorphisms of MTHFR gene associate with the risk to develop postpartum depression.

Method: 434 women were recruited in a study period of 3 years (January 2014 to December 2017) in a tertiary care centre. EPDS was administered at 6 weeks postpartum, with a cut-off score of $\geq 10$ to define probable postpartum depression. Plasma was used for the estimation of circulating vitamin B12 metabolites and whole blood for extraction of DNA. Real time PCR using Taqman probes was used for genotyping the proposed SNP's.

Results: T allele of MTHFR C677T was associated with the risk of probable PPD ( $p=0.024, \mathrm{OR}=1.67$; $95 \% \mathrm{Cl}: 1.06-2.62)$ and presence of suicidal ideations in these women $(p<0.001, \mathrm{OR}=2.90 ; 95 \% \mathrm{Cl}: 1.61-$ 5.24). Haplotype 677T-1298A was associated with both the risk of probable PPD $(p=0.029, O R=1.66$; $95 \% \mathrm{Cl}: 1.05-2.64)$ and suicidal ideations $(\mathrm{p}<0.001, \mathrm{OR}=2.933 ; 95 \% \mathrm{Cl}: 1.60-5.35)$, whereas $677 \mathrm{C}-1298 \mathrm{~A}$ was protective against suicidal ideations $(p=0.011 ; \mathrm{OR}=0.558 ; 95 \% \mathrm{Cl}$ : 0.35-0.88). Women with risk allele $T$ were also associated with higher levels of circulating holotranscobalamin levels, and lower levels of vitamin B12, whereas risk allele C of A1298C had lower levels of holotranscobalamin.

Limitations: Cross-sectional study

Conclusion: Polymorphic variants of MTHFR gene might indicate susceptibility to develop probable depression in postpartum period.

Significance

MTHFR C677T has been widely reported in the literature to be associated with general depression. The association of this variant in susceptibility to develop postpartum depression is not widely studied. We observed T allele of MTHFR C677T to be associated with the risk of to develop depression and suicidal ideation in postpartum period. Higher levels of MMA and holotranscobalamin, and lower levels of vitamin B12 were associated with T allele of MTHFR C677T. Polymorphic variants of MTHFR gene might indicate susceptibility to develop depression in postpartum period.

\section{Introduction}

Postpartum depression (PPD) is a common complication of pregnancy, affecting about $19 \%$ of women in developing countries like India (Upadhyaya et al, 2017). Depressed maternal mood is known to affect growth and development of the child adversely (McManus and Poehlmann, 2012). Although many factors attribute to the development of PPD, nutritional factors are widely accepted as modifiable, yet vital in the development of PPD (Bodnar and Wisner, 2005; Leung and Kaplan, 2009). Of the many macro- 
and micronutrients implicated in perinatal depression, the water-soluble B-vitamins are reported consistently in literature (Leung and Kaplan, 2009). Vitamin B12 and folate, which directly influence the production and bioavailability of serotonin, and prevent the excess accumulation of neurotoxin homocysteine (hcy), are one such example (Abou-Saleh et al., 1999; Chong et al., 2014; Peppard et al., 2019). Both these vitamins play a crucial rule in the remethylation of cellular hcy to methionine, which further leads to the synthesis of S-adenosyl methionine (SAM). SAM is responsible for non-genomic methylations essential for neurotransmitter synthesis and genomic methylation, which regulated reuptake of neurotransmitters. Degradation of hcy also protects the cells from its excess, which can disrupt oxidative state of the cell (Fox and Stover, 2008).

Certain enzymes and proteins play a crucial role in maintaining the optimum cellular concentration and functions of folate and vitamin B12. Reduced activity of methylene tetrahydrofolate reductase (MTHFR) enzyme, a major regulatory enzyme of folate-B12-methionine cycle is associated with depression in general population (Lok et al, 2013; Peerbooms et al, 2011). C677T and A1298C are the most common polymorphic forms of MTHFR gene loci. Both these single nucleotide polymorphism (SNPs) are exonic in location, causing production of a thermolabile enzyme that degrades faster; hence, they can influence intracellular concentration of metabolites like hcy, along with decreased regeneration of methionine (Frosst et al., 1995; Weisberg et al.,1998).

Present literature has limited studies on the effect of MTHFR C677T and A1298C on postpartum depression. In a prospective study carried out by Lewis et al. in 6809 pregnant women (both folate supplemented and non-supplemented), supplementation of folate in pregnancy protected the women from postpartum depression, especially women with the risk genotype i.e. MTHFR C677T TT (Lewis et al., 2012).

We hypothesize that the polymorphic variants of MTHFR (C677T and A1298C) are associated with the susceptibility to develop postpartum depression in South Indian women. Therefore, in the present study, we aimed to explore the association of MTHFR C677T and A1298C genotypes on probable postpartum depression. We also analyzed the effect of these polymorphisms on the circulating folate and vitamin B12 metabolites.

\section{Material And Method \\ 2.1 Study design}

We conducted this case-control study in JIPMER, a tertiary care hospital in the south of India with approximately 20,000 deliveries per year (jipmer.edu.in). Archived samples of extracted DNA and plasma from a previous parent study (communicated elsewhere) were used with convenient sampling. Parent study was approved by Institute ethics committee (Ref no-JIP/IEC/2014/5/319) and was conducted according to the principles expressed in Declaration of Helsinki. 
We calculated the sample size for genetic polymorphism using 0.12 as the minor allele frequency of MTHFR gene in Indian population (Sukla and Raman, 2012), and the disease prevalence of $26.3 \%$ as reported by Savarimuthu et al., (Savarimuthu et al, 2010) in the software Genetic Power Calculator (Purcell et al, 2003). Sample size was estimated at $5 \%$ level of significance with $80 \%$ power. Estimated sample size considered was 217 subjects in each group (total 434 study subjects) to fulfill one of the study objectives of genotype-phenotype interaction. Written informed re-consent was obtained prior to including women in the present study.

We defined probable PPD as Edinburg Postpartum Depression Scale (EPDS), score of $\geq 10$, which has shown good validity in measuring depressive symptoms during pregnancy and postnatal depression in this population (Benjamin et al., 2005; Cox et al., 1987). Further group stratification was done in cases based on presence or absence of suicidal ideation, which was assessed on EPDS item 10: "The thought of harming myself has occurred to me" (yes, quite often; sometimes; hardly ever; never). We excluded women with previous history of depression. Socio-demographic, obstetric and psychiatric history associated with PPD was collected. Women included in the study had their antenatal follow up and delivery in JIPMER, where folate supplements are provided by the hospital as a part of patient care. At this point, we collected $5 \mathrm{ml}$ of venous blood in EDTA vial for plasma metabolites and genotyping.

\subsection{Genotyping}

We checked the quality of extracted DNA using NanoDrop ${ }^{\mathrm{TM}} 2000$ (Thermo Fisher Scientific Inc., USA) and a minimum 260:280 ratio of $>1.8$ acceptable for SNP studies. Samples with a ration of less than 1.8 were re-extracted by commercially available extraction kits (QIAmp DNA Blood mini kit, Qiagen, Germany). Genotyping for Single Nucleotide Polymorphisms (SNP) MTHFR C677T (assay ID C-1202883-20) and A1298C (assay id C-850486-20) was performed using a Taqman SNP genotyping assay in CFX 96 (BioRad Laboratories Inc., USA), using an allelic discrimination mode. In all, 50 ng DNA was amplified in a $10 \mu \mathrm{L}$ reaction mixture containing $5 \mu \mathrm{L}$ of Taqman genotyping master-mix (Applied Biosystems), $0.25 \mu \mathrm{L}$ ( $5 \mathrm{pmol}$ ) of each primer \& probe (Applied Biosystems), and $3.75 \mu \mathrm{L}$ of nuclease free water. The amplification conditions consisted of denaturation at $95^{\circ} \mathrm{C}$ for 10 minutes followed by 40 cycles of denaturation at $95^{\circ} \mathrm{C}$ for 15 seconds, and then by annealing and elongation at $65^{\circ} \mathrm{C}$ for 60 seconds. Genotype call rate for both $\mathrm{C} 677 \mathrm{~T}$ and $\mathrm{A} 1298 \mathrm{C}$ was $100 \%$.

\subsection{Measurement of folate and vitamin B12 metabolites in circulation}

Plasma was separated by centrifugation at $2000 \mathrm{~g}$ for 15 minutes and stored at $-80 \mathrm{C}$ till further analysis. Determination of vitamin B12, holotranscobalmin (holotc), 5-methyl THF, SAM, Hcy, Methyl malonyl Co-A (MMA), and serotonin in plasma was performed using commercially available ELISA kits.

\subsection{Statistical methods}

We used chi-square test for categorical variables and student $t$ test for continuous variables using SPSS version 20.0 (SPSS Inc., Chicago, USA). To find the Hardy-Weinberg equilibrium (HWE), and the difference 
in both allele and genotype frequency, we used chi-square test using online calculator DeFinetti (http://ihg.gsf.de/cgi-bin/hw/hwa1.p1). Further, association of MTHFR genotypes with the risk for probable PPD was carried out by logistic regression analysis by creating dominant, recessive \& additive models that was adjusted to significantly different socio-demographic, obstetric and nutritional factors between two groups. Correction for multiple testing was carried out by Bonferroni's method. The results were expressed as percentage, odds ratio (OR) and their $95 \%$ confidence intervals. Combined genotype frequencies were calculated by direct counting. Haplotype frequencies were estimated and linkage disequilibrium (LD test was performed in Haploview 4.1 software, and further verified in online using the software SHEsis (Barrett et al., 2005; Shi and He, 2005).

\section{Results}

\subsection{Population Characteristics}

The mean age of the women in the study cohort was $26 \pm 4.2$ years. We observed no significant difference between maternal ages $(t(432)=-1.639, p=0.102)$. Maternal BMI (at 6-weeks postpartum) was also found not to be statistically different between study groups $(t(432)=1.214, p=0.225)$. We found significant percentages of postpartum women with probable PPD to belong to middle class group $(\chi(4)=$ $17.53, p=0.002)$. Stress variables like marital dissatisfaction was observed to be higher in depressed women $(\chi(1)=62.77, p<0.0001)$. Among the obstetric factors, women with probable PPD were multiparous $(\chi(2)=12.60, p=0.002)$, had a higher number of unplanned pregnancy $(\chi(1)=16.92, p<$ $0.001)$ and instrumental delivery $(\chi(2)=8.49, p=0.014)$, and were dissatisfied with the baby's gender $(\chi(1)=8.244, p=0.006)$.

Majority of our study population (94.5\%) was reported to be on mixed diet. Women with probable PPD consumed meat $(\chi(2)=7.61, p=0.022)$, egg $(\chi(2)=73.40, p<0.001)$ and curd $(\chi(2)=12.92, p=0.002)$ in lesser frequency than controls.

\subsection{Single locus analysis}

Both MTHFR C677T and A1298C were in Hardy Weinberg Equilibrium ( $\mathrm{p}=0.116$ and 0.812 respectively) in healthy controls. Among the two SNP's, the minor allele of MTHFR C677T significantly associated with the risk for probable PPD ( $p=0.024, \mathrm{OR}=1.67 ; 95 \% \mathrm{Cl}$ : 1.06-2.62) (Table 1). Homozygous risk genotype (TT) of MTHFR C677T was more common in women with probable PPD $(\mathrm{p}=0.041)$, whereas we observed no such difference in case of MTHFR A1298C $(p=0.955)$ (Table 1$)$. 
Table 1

Distribution of genotype and allele frequency of MTHFR C677T and A1298C and their association with risk of probable postpartum depression

\begin{tabular}{|c|c|c|c|}
\hline $\begin{array}{l}\text { MTHFR } \\
\text { C677T }\end{array}$ & $\begin{array}{l}\text { Women without probable } \\
\text { PPD } \\
(n=217)\end{array}$ & $\begin{array}{l}\text { Women with probable } \\
\text { PPD } \\
(n=217)\end{array}$ & P-value (0R;95\% Cl) \\
\hline \multicolumn{4}{|c|}{ Genotype frequency n (\%) } \\
\hline $\mathrm{CC}$ & $186(85.7 \%)$ & $173(79.7 \%)$ & \multirow{3}{*}{$\begin{array}{l}\text { Heterozygous } \\
\mathrm{P}=0.335(1.306 ; 0.76-2.24) \\
\text { Homozygous }\end{array}$} \\
\hline & & \multirow{2}{*}{$34(15.7 \%)$} & \\
\hline CT & $28(12.9 \%)$ & & \\
\hline TT & $3(1.3 \%)$ & $10(4.6 \%)$ & $\begin{array}{l}P=0.0417 *(3.584 ; 0.970- \\
13.239)\end{array}$ \\
\hline \multicolumn{4}{|c|}{ Allele frequency n (\%) } \\
\hline C & $400(92.1 \%)$ & $380(87.5 \%)$ & \multirow{2}{*}{$\begin{array}{l}P=0.0245 *(1.672 ; 1.064- \\
2.626)\end{array}$} \\
\hline $\mathrm{T}$ & $34(7.8 \%)$ & $54(12.4 \%)$ & \\
\hline \multicolumn{4}{|c|}{ MTHFR A1298C } \\
\hline \multicolumn{4}{|c|}{ Genotype frequency n (\%) } \\
\hline AA & $70(32.3 \%)$ & $76(35 \%)$ & \multirow{2}{*}{$\begin{array}{l}\text { Heterozygous } \\
P=0.407(1.016 ; 0.547- \\
1.278)\end{array}$} \\
\hline \multirow[t]{2}{*}{$A C$} & $108(49.8 \%)$ & $98(45.2 \%)$ & \\
\hline & & & \multirow{2}{*}{$\begin{array}{l}\text { Homozygous } \\
P=0.955(1.306 ; 0.591- \\
1.745)\end{array}$} \\
\hline $\mathrm{CC}$ & $39(18 \%)$ & $43(19.8 \%)$ & \\
\hline \multicolumn{4}{|c|}{ Allele frequency $\mathrm{n}(\%)$} \\
\hline A & $248(57.1 \%)$ & $250(57.6 \%)$ & \multirow[t]{2}{*}{$P=0.890(0.980 ; 0.75-1.28)$} \\
\hline C & $186(42.8 \%)$ & $184(42.3 \%)$ & \\
\hline
\end{tabular}

Genetic association analyses adjusted for covariates (socioeconomic status, marital dissatisfaction, parity, pregnancy planning, type of delivery, self-satisfaction with baby's gender and nutritional factors) and corrected for multiple testing showed significantly increased risk of probable PPD for MTHFR C677T under additive model, whereas we observed no such association for MTHFR A1298C (Table 2). 
Table 2

Genotypic associations of MTHFR C677T and A1298C with probable postpartum depression under additive, dominant and recessive models

\begin{tabular}{|c|c|c|c|c|c|c|c|}
\hline \multirow[t]{2}{*}{ SNP } & \multirow{2}{*}{$\begin{array}{l}\text { Reference } \\
\text { genotype }\end{array}$} & \multicolumn{2}{|c|}{ Additive model ${ }^{\#}$} & \multicolumn{2}{|c|}{ Dominant model } & \multicolumn{2}{|c|}{ Recessive model } \\
\hline & & $\mathrm{P}^{\$}$ & $\begin{array}{l}\text { OR } \\
(95 \% \mathrm{Cl})\end{array}$ & $\mathrm{P}^{\$}$ & $\begin{array}{l}\text { OR } \\
(95 \% \mathrm{Cl})\end{array}$ & $\mathrm{P}^{\$}$ & $\begin{array}{l}\text { OR } \\
(95 \% \mathrm{Cl})\end{array}$ \\
\hline $\begin{array}{l}\text { MTHFR } \\
\text { C677T }\end{array}$ & $\mathrm{CC}$ & $0.042^{*}$ & $\begin{array}{l}1.7 \\
(1.11-2.62)\end{array}$ & 0.135 & $\begin{array}{l}1.7(1.01- \\
2.88)\end{array}$ & 0.078 & $\begin{array}{l}4.52(1.2- \\
17.0)\end{array}$ \\
\hline $\begin{array}{l}\text { MTHFR } \\
\text { A1298C }\end{array}$ & AA & 0.987 & $\begin{array}{l}0.862(0.641- \\
1.16)\end{array}$ & 0.630 & $\begin{array}{l}0.79(0.49- \\
1.16)\end{array}$ & 0.840 & $\begin{array}{l}0.945(0.54- \\
1.63)\end{array}$ \\
\hline \multicolumn{8}{|c|}{ Abbreviations: OR $(95 \% \mathrm{Cl})$, odds ratio (95\% confidence interval) } \\
\hline \multicolumn{8}{|c|}{$\begin{array}{l}\text { \#P value and } \mathrm{OR}(95 \% \mathrm{Cl}) \text { from logistic regression after adjustment for socio-demographic, obstetrics } \\
\text { and nutritional factors }\end{array}$} \\
\hline \multicolumn{8}{|c|}{ * Significant $P<0.05$} \\
\hline$\$$ Correct & for multiple & & & & & & \\
\hline
\end{tabular}

Stratification of cases by presence or absence of suicidal ideations (item 10 of EPDS) revealed a significant difference in the genotype and allele frequency of MTHFR C677T, with T allele being significantly associated with the risk of suicidal ideation (Table 3 ). We found no difference in genotype or allele frequency of A1298C in suicidal ideations (Table 3). 
Table 3

Distribution of genotype and allele frequency of MTHFR C677T and A1298C and their association with risk of suicidal ideation in women with probable postpartum depression

\begin{tabular}{|c|c|c|c|}
\hline $\begin{array}{l}\text { MTHFR } \\
\text { C677T }\end{array}$ & $\begin{array}{l}\text { Women without suicidal } \\
\text { ideation } \\
(n=164)\end{array}$ & $\begin{array}{l}\text { Women with suicidal } \\
\text { ideation } \\
(n=53)\end{array}$ & P-value (OR;95\% Cl) \\
\hline \multicolumn{4}{|c|}{ Genotype frequency n (\%) } \\
\hline $\mathrm{CC}$ & $137(83.5 \%)$ & $36(67.9 \%)$ & \multirow{2}{*}{$\begin{array}{l}\text { Heterozygous } \\
P=0.270(1.58 ;(0.69- \\
3.61)\end{array}$} \\
\hline \multirow{2}{*}{ СT } & $24(14.6 \%)$ & $10(18.9 \%)$ & \\
\hline & & & \multirow{2}{*}{$\begin{array}{l}\text { Homozygous } \\
P=<0.001 *(8.8 ; 2.18- \\
36.06)\end{array}$} \\
\hline TT & $3(1.8 \%)$ & $7(13.2 \%)$ & \\
\hline \multicolumn{4}{|c|}{ Allele frequency $\mathrm{n}(\%)$} \\
\hline C & $277(84.9 \%)$ & $79(74.5 \%)$ & \multirow{2}{*}{$\begin{array}{l}P=<0.001 *(2.90 ; 1.61- \\
5.24)\end{array}$} \\
\hline $\mathrm{T}$ & $51(15.6 \%)$ & $27(25.4 \%)$ & \\
\hline \multicolumn{4}{|c|}{ MTHFR A1298C } \\
\hline \multicolumn{4}{|c|}{ Genotype frequency $n(\%)$} \\
\hline AA & $57(34.8 \%)$ & $19(35.8 \%)$ & \multirow{2}{*}{$\begin{array}{l}\text { Heterozygous } \\
P=0.694(0.868 ; 0.43- \\
1.75))\end{array}$} \\
\hline \multirow[t]{2}{*}{$A C$} & $76(46.3 \%)$ & $22(41.5 \%)$ & \\
\hline & & & \multirow{2}{*}{$\begin{array}{l}\text { Homozygous } \\
P=0.728(1.16 ; 0.49- \\
2.70)\end{array}$} \\
\hline $\mathrm{CC}$ & $31(18.9 \%)$ & $12(22.6 \%)$ & \\
\hline \multicolumn{4}{|c|}{ Allele frequency n (\%) } \\
\hline A & $190(57.9 \%)$ & $60(56.6 \%)$ & \multirow{2}{*}{$\begin{array}{l}P=0.810(1.05 ; 0.678- \\
1.64)\end{array}$} \\
\hline C & $138(42.0 \%)$ & $46(43.3 \%)$ & \\
\hline
\end{tabular}

The genetic association analyses suggested that MTHFR C677T was significantly associated with suicidal ideations in women with probable PPD under dominant model (Table 4). We observed no such association with MTHFR A1298C. 
Table 4

Genotypic associations of MTHFR C677T and A1298C with suicidal ideations in women with probable postpartum depression under additive, dominant and recessive models

\begin{tabular}{|c|c|c|c|c|c|c|c|}
\hline \multirow[t]{2}{*}{ SNP } & \multirow{2}{*}{$\begin{array}{l}\text { Reference } \\
\text { genotype }\end{array}$} & \multicolumn{2}{|c|}{ Additive model ${ }^{\#}$} & \multicolumn{2}{|c|}{ Dominant model } & \multicolumn{2}{|c|}{ Recessive model ${ }^{\#}$} \\
\hline & & $\mathbf{P}^{\$}$ & $\begin{array}{l}\text { OR } \\
(95 \% \mathrm{Cl})\end{array}$ & $\mathrm{P}^{\$}$ & $\begin{array}{l}\text { OR } \\
(95 \% \mathrm{Cl})\end{array}$ & P\$ & $\begin{array}{l}\text { OR } \\
(95 \% \mathrm{Cl})\end{array}$ \\
\hline $\begin{array}{l}\text { MTHFR } \\
\text { C677T }\end{array}$ & $\mathrm{CC}$ & 0.057 & $\begin{array}{l}1.97 \\
(1.11-3.47)\end{array}$ & $0.039^{*}$ & $\begin{array}{l}2.5(1.21- \\
5.5)\end{array}$ & 0.678 & $\begin{array}{l}2.34 \\
(0.58- \\
9.36)\end{array}$ \\
\hline $\begin{array}{l}\text { MTHFR } \\
\text { A1298C }\end{array}$ & AA & 0.954 & $\begin{array}{l}0.76(0.45- \\
1.29)\end{array}$ & 0.879 & $\begin{array}{l}0.672(0.32- \\
1.41)\end{array}$ & 0.639 & $\begin{array}{l}0.79(0.31- \\
2.05)\end{array}$ \\
\hline \multicolumn{8}{|c|}{ Abbreviations: OR $(95 \% \mathrm{Cl})$, odds ratio (95\% confidence interval) } \\
\hline \multicolumn{8}{|c|}{$\begin{array}{l}\text { \#P value and } \mathrm{OR}(95 \% \mathrm{Cl}) \text { from logistic regression after adjustment for socio-demographic, obstetrics } \\
\text { and nutritional factors }\end{array}$} \\
\hline \multicolumn{8}{|c|}{ * Significant $P<0.05$} \\
\hline \$ Correct & or multipl & & & & & & \\
\hline
\end{tabular}

\subsection{Combined genotypes}

In the whole cohort, we observed four common combined genotypes-CC/AC (42.3\%), CC/AA (22.8\%), CC/CC (18.2\%) and CT/AA (8.7\%). The distribution of combined genotype did not vary between women with and without probable PPD $(p=0.348)$.

\subsection{Haplotypes}

Table 5 summarizes the results of $L D$ analyses and haplotype frequencies of both the polymorphisms of MTHFR gene. We found MTHFR C677T and A1298C to be at high linkage disequilibrium $\left(D^{\prime}=0.88 ; r 2=\right.$ 0.066), with haplotype "677C-1298A" to be the most common in our cohort. The distribution of haplotype frequencies was also different between two groups with "677T-1298A" being more prevalent in women with probable PPD (Table 5). 
Table 5

Estimated haplotype frequencies and the results from linkage disequilibrium test of MTHFR C677T and A1298C polymorphisms in women with and without probable depression

\begin{tabular}{|c|c|c|c|c|c|}
\hline $\begin{array}{l}\text { Compound } \\
\text { genotypes }\end{array}$ & $\begin{array}{l}\text { Frequency in women with } \\
\text { probable depression } \\
(n=217)\end{array}$ & $\begin{array}{l}\text { Frequency in } \\
\text { women without } \\
\text { probable } \\
\text { depression } \\
(n=217)\end{array}$ & $\begin{array}{l}\text { OR } \\
(95 \% \\
\text { Cl) }\end{array}$ & $\begin{array}{l}\mathrm{p}- \\
\text { value }\end{array}$ & $\begin{array}{l}\text { Linkage } \\
\text { Disequilibrium } \\
\text { test }\end{array}$ \\
\hline $677 C-1298 \mathrm{~A}$ & $45.8 \%$ & $49.7 \%$ & $\begin{array}{l}0.859 \\
(0.65- \\
1.12)\end{array}$ & 0.251 & $\begin{array}{l}D^{\prime}=0.88 \\
r 2=0.066\end{array}$ \\
\hline $677 C-1298 \mathrm{C}$ & $41.8 \%$ & $42.5 \%$ & $\begin{array}{l}0.975 \\
(0.745- \\
1.27)\end{array}$ & 0.830 & \\
\hline 677T-1298A & $11.8 \%$ & $7.5 \%$ & $\begin{array}{l}1.66 \\
(1.05- \\
2.64)\end{array}$ & $0.029 *$ & \\
\hline
\end{tabular}

On stratification of women with probable PPD by the presence or absence of suicidal ideation, haplotype "677T-1298A" conferred a high risk for suicidal ideation, whereas "677C-1298A" was found to be protective (Table 6). 
Table 6

Estimated haplotype frequencies and linkage disequilibrium test of MTHFR C677T and A1298C polymorphisms in sub-groups based on presence or absence of suicidal ideation in women with probable PPD

\begin{tabular}{|c|c|c|c|c|}
\hline $\begin{array}{l}\text { Compound } \\
\text { genotype }\end{array}$ & $\begin{array}{l}\text { Frequency in women with } \\
\text { suicidal ideation } \\
(n=53)\end{array}$ & $\begin{array}{l}\text { Frequency in women } \\
\text { without } \\
\text { suicidal ideation } \\
(n=164)\end{array}$ & $\begin{array}{l}\text { OR } \\
(95 \% \mathrm{Cl})\end{array}$ & p-value \\
\hline $677 \mathrm{C}-1298 \mathrm{~A}$ & $35 \%$ & $49.3 \%$ & $\begin{array}{l}0.558 \\
(0.35- \\
0.88)\end{array}$ & $0.011^{\star}$ \\
\hline $677 C-1298 C$ & $42.3 \%$ & $41.6 \%$ & $\begin{array}{l}1.04 \\
(0.66- \\
1.62)\end{array}$ & 0.85 \\
\hline 677T-1298A & $21.6 \%$ & $8.6 \%$ & $\begin{array}{l}2.933 \\
(1.60- \\
5.35)\end{array}$ & $0.0003^{*}$ \\
\hline
\end{tabular}

\subsection{Association of MTHFR gene polymorphisms with circulating vitamin B12 metabolites}

A Kruskal - Wallis $\mathrm{H}$ test was run to determine if there were differences in the metabolite levels among MTHFR genotypes. In the whole cohort $(\mathrm{n}=434)$, we observed risk allele T of MTHFR C677T to be associated with higher levels of holotc (Fig. 1). Pair wise analysis of holotc showed significant differences between CC versus TT genotypes $(p=0.045)$, and CT versus TT genotypes $(p=0.044)$. Lower vitamin B12 levels were observed with the T allele of MTHFR C677T, although it was not statistically significant (Fig. 1). On the other hand, risk allele C of MTHFR A1298C associated with lower holotc levels (Fig. 2). MTHFR A1298C genotype did not show significant associations with any other circulating metabolite.

\section{Discussion}

Decreased cellular activities of folate and vitamin B12 play an important role in the pathogenesis of depression in perinatal period (Abou Saleh et al., 1995; Bodnar and Wisner, 2005; Leung and Kaplan, 2009). Functional polymorphisms of MTHFR gene might impact folate and vitamin B12 metabolism, as it is a key enzyme responsible for maintaining the active 5-methyl form of THF. In the present study, we explored the association between two common functional MTHFR gene polymorphisms i.e., C677T and 
A1298C with depressive symptoms in postpartum period, and analyzed the circulating levels of vitamin B12 and folate metabolites in circulation in South Indian Women.

Our results showed that the T allele of MTHFR C677T has association with the risk and severity (in terms of suicidal ideations) of PPD. Women with the risk allele T had higher levels of holotc, and lower levels of vitamin B12. Further, haplotype 677T-1298A associated with both the risk of probable PPD and suicidal ideations, whereas $677 \mathrm{C}-1298 \mathrm{~A}$ was found to be protective against suicidal ideations. These findings support our hypothesis that polymorphic variants of MTHFR gene might be associated with probable depression in postpartum period.

Similar to our study, T allele of MTHFR C677T associated with general depression in Irish (Kelly et al., 2004), Norway (Folate, 2003), and Chinese Han populations (Shen, 2014). Gilbody et al., in their metareview of MTHFR polymorphisms with psychiatric disorders observed an odd's ratio of 1.36 (1.11-1.67) for homozygous variant (TT) of C677T compared to wild type (CC) in 1280 patients with unipolar depression (Gilbody et al., 2007). Furthermore, an association between MTHFR C677T with the risk of postmenopausal depression (Stopien et al., 2008) and depression related to childhood trauma (Lok et al., 2013) is also reported.

Although, many genetic variants are implicated in PPD, studies on the effect of MTHFR gene polymorphisms are limited. Lewis et al. in their recent study on 6809 pregnant women, observed that women with susceptible MTHFR C677T TT genotype were protected from postpartum depression at 21 months postpartum, by supplementing them with folate in pregnancy (Lewis et al., 2012).

We observed self-harm ideations in $24.4 \%$ of women who had an EPDS score of over 10 . Wisner et al. (19.9\%) and Lindahl et al. (20\%) have observed similar results in American population (Lindahl et al., 2005; Wisner et al,. 2013). We also observed increased risk of suicidal ideations in women carrying $T$ allele of MTHFR C677T gene. To the best of our knowledge this is the first report of such association. Recent studies have reported the role of polymorphisms in oxytocin receptor gene, CD38, Monoamine oxidase - A (MAO-A), Monoamine oxidase-B (MAO-B) and hypermethylation of TrK and Brain derived neurotrophic factor (BDNF) gene to be associated with suicidality (Balestri et al., 2017; Lockwood et al., 2015; Parris et al., 2018). None of the above studies targeted women in postpartum period. As suicides represent second most common cause of mortality in the postpartum period (Appleby, 1998), and folate supplementation can modulate the effect of MTHFR polymorphic variants, the observations of our study might be useful in recognizing the severity of PPD.

We found that haplotype 677T-1298A to be associated with the risk of probable PPD. It also conferred a high risk for suicidal ideation, whereas 677C-1298A was found to be protective against severe PPD. No study to date has examined the association of these haplotypes with the risk and severity of depressive symptoms in postpartum period.

On analyzing the association of MTHFR C677T and A1298C with circulating folate and vitamin B12 metabolites, we observed that the risk allele T of MTHFR C677T associated with higher levels of holotc 
and lower levels of vitamin B12 (Figure 1), whereas risk allele C of MTHFR A1298C associated with lower holotc levels (Fig 2). Rise of holotc levels with the risk allele of MTHFR C677T might be interpreted as a compensatory mechanism of the body to decreased vitamin B12 levels. The effect of MTHFR A1298C on vitamin B12 and holotc levels need to be confirmed further in larger prospective studies.

Strength of this study is the inclusion of ethnically similar population (Dravidians), where all the women received folate supplementation during pregnancy.

One limitation of our study is its cross-sectional nature. As, we could not follow these women for a longer time; effect of MTHFR genotype on the progression of probable PPD could not be determined. Also, there may be other social factors contributing to depression in postpartum period other than the ones collected by us in the study, which may influence the results.

\section{Conclusions}

In conclusion, we observed T allele of MTHFR C677T and 677T-1298A compound genotype to be associated both with the risk of developing probable depression and suicidal ideations in the postpartum period. Haplotype 677C-1298A was protective against the risk of suicidal ideations. Risk allele T MTHFR C677T was also associated with increased holotc levels and decreased vitamin B12 levels. These preliminary results might carry a translational value in recognizing women susceptible to depression in postpartum period and should be confirmed further in larger, prospective studies.

\section{Declarations}

\section{Acknowledgement}

This work was funded by Department of Science and Technology (DST), India under the scheme Women scientist on break (WOS-A)- Reference No: SR/WOS-A/LS-299/2016(G) dated 25.07.2017). DST had no further role in study design; in the collection, analysis and interpretation of data; in the writing of the report; and in the decision to submit the paper for publication.

\section{Conflict of interest}

The authors declare no conflict of interest

\section{Author Contribution}

SR designed the study.

NP screened the women for probable PPD. 
RR and ABW collected blood samples, separated the plasma and extracted DNA for storage. PD performed ELISA \& genotyping and statistical analysis of the data. PD wrote the manuscript.

BB and VP coordinated blood samples and study data.

SR had primary responsibility for final content of the manuscript.

\section{References}

1. Abou-Saleh MT, Ghubash R, Karim L, et al . The role of pterions and related factors in the biology of early postpartum depression. European Neuropsychopharmacology, 1999,9,295-300.

2. Appleby L. Suicide and other cause of mortality after post-partum psychiatric admission. British Journal of Psychiatry, 1998, 173, 209-11.

3. Balestri M,Calati R, Serretti A et al. Maoa and Maob polymorphisms and personality traits in suicide attempters and healthy controls: a preliminary study. Psychiatry Res., 2017, 249, 212-217.

4. Barrett JC, Fry B, Maller J et al. "Haploview: analysis and visualization of LD and haplotype maps". Bioinformatics, 2005, 21, 263-5.

5. Benjamin D, Chandramohan A, Annie IK, et al. Validation of the Tamil version of Edinburgh postpartum depression scale. Journal of Obstetrics and Gynecologist India, 2005, 55, 241-243.

6. Bodnar LM, Wisner KL. Nutrition and depression: implications for improving mental health among childbearing-aged women. Biological Psychiatry, 2005, 58, 679-85.

7. Chong MFF, Wong JXY, Colega M, et al. Relationships of maternal folate and vitamin B12 status during pregnancy with perinatal depression: The GUSTO study. Journal of Psychiatry Research, 2014, 1-7.

8. Cox JL, Holden JM, Sagovsky R. Detection of postnatal depression. Development of the 10-item Edinburgh postnatal depression scale. British Journal of Psychiatry,1987,150,782-86.

9. Folate EVS. Vitamin B12 and homocysteine, and the MTHFR 677C $>$ T polymorphism in anxiety and depression. The Hordaland Homocysteine Study. Archives of General Psychiatry, 2003,60,618-626.

10. Fox JT, Stover PJ. Folate-mediated one-carbon metabolism. Vitamins and Hormones, 2008, 79, 1-44.

11. Frosst $P$, Blom $H$ J, Milos $R$, et al. A candidate genetic risk factor for vascular disease; a common mutation in methylenetetrahydrofolate reductase. Nature Genetics, 1995, 10, 111-13.

12. Gilbody S, Lewis S, Lightfoot T. Methylenetetrahydrofolate Reductase (MTHFR) genetic polymorphisms and psychiatric disorders: A HuGE review. American Journal of Epidemiology, 2007, $165,1-13$.

13. Kelly CB, McDonnell AP, Johnston TG, et al. The MTHFR C677T polymorphism is associated with depressive episodes in patients from Northern Ireland. Journal of Psychopharmacology, $2004,18,567$.

14. Leung BM, Kaplan BJ. Perinatal depression: prevalence, risks, and the nutrition link-a review of the literature. Journal of American Dietic Association, 2009, 109, 1566-75. 
15. Lewis SJ,Araya R, Leary $\mathrm{S}$ et al. Folic acid supplementation during pregnancy may protect against depression 21 months after pregnancy, an effect modified by MTHFR C677T genotype. European Journal of Clinical Nutrition, 2012, 66, 97-103.

16. Lindahl V, Pearson JL, Colpe L. Prevalence of suicidality during pregnancy and the postpartum. Archives of Women's Mental Health, 2005, 8, 77-87.

17. Lockwood LE,Su S, Youssef NA. The role of epigenetics in depression and suicide: A platform for gene-environment interactions. Psychiatry Research, 2015, 228, 235-42.

18. Lok A, Bockting CL, Koeter MW, et al. Interaction between the MTHFR C677T polymorphism and traumatic childhood events predicts depression. Translational Psychiatry, 2013, 3, e288.

19. McManus BM, Poehlmann J. Parent-child interaction, maternal depressive symptoms and preterm infant cognitive function. Infant Behaviour Development, 2012, 35, 489-98.

20. Parris MS,Grunebaum MF, Galfalvy HC. Attempted suicide and oxytocin-related gene Journal of Affective Disorder, 2018, 238, 62-68.

21. Peerbooms OL, van Os, J, Drukker M, et al. MTHFR in Psychiatry Group. Meta-analysis of MTHFR gene variants in schizophrenia, bipolar disorder and unipolar depressive disorder: Evidence for a common genetic vulnerability? Brain Behaviour Immunology, 2011,25, 1530-43.

22. Peppard L, Oh KM, Gallo S, Milligan R. Risk of depression in pregnant women with low-normal serum vitamin B12. Research in Nursing and Health, 2019, 1-9.

23. Purcell S, Cherny SS, Sham PC. Genetic Power Calculator: design of linkage and association genetic mapping studies of complex traits. Bioinformatics, 2003, 19, 149-150.

24. Savarimuthu RJ, Ezhilarasu P, Charles $\mathrm{H}$, et al. Post-partum depression in the community: a qualitative study from rural South India. International Journal of Social Psychiatry, 2010, 56, 94-102.

25. Shen X, Wu Y, Guan T, et al. Association analysis of COMT/MTHFR polymorphisms and major depressive disorder in Chinese Han population. Journal of Affective Disorder, 2014, 161, 73-78.

26. Shi YY, He L. SHEsis, a powerful software platform for analyses of linkage disequilibrium, haplotype construction, and genetic association at polymorphism loci. Cell Research, 2005, 15, 97-8.

27. Słopien RK, Meczekalski JB, Warenik-Szymankiewicz A, et al. Polymorphic variants of genes encoding MTHFR, MTR, and MTHFD1 and the risk of depression in postmenopausal women in Poland. Maturitas, 2008, 61, 252-255.

28. Sukla KK, Raman R. Association of MTHFR and RFC1 gene polymorphism with hyperhomocysteinemia and its modulation by vitamin B12 and folic acid in an Indian population. European Journal of Clinical Nutrition, 2012, 66, 111-18.

29. Upadhyay RP, Chowdhury R, Salehi A, et al. Postpartum depression in India: a systematic review and meta-analysis. Bulletin World Health Organisation,2017, 95, 706-717C. 
30. Weisberg I, Tran P, Christensen B, et al. A second genetic polymorphism in MTHFR associated with decreased enzyme activity. Molecular Genetics and Metabolism, 1998, 64, 169-72.

31. Wisner K L, Sit D K, McShea M C, et al. Onset timing, thoughts of self-harm, and diagnoses in postpartum women with screen-positive depression findings. Psychiatry, 2013, 70, 490-498.

\section{Figures}
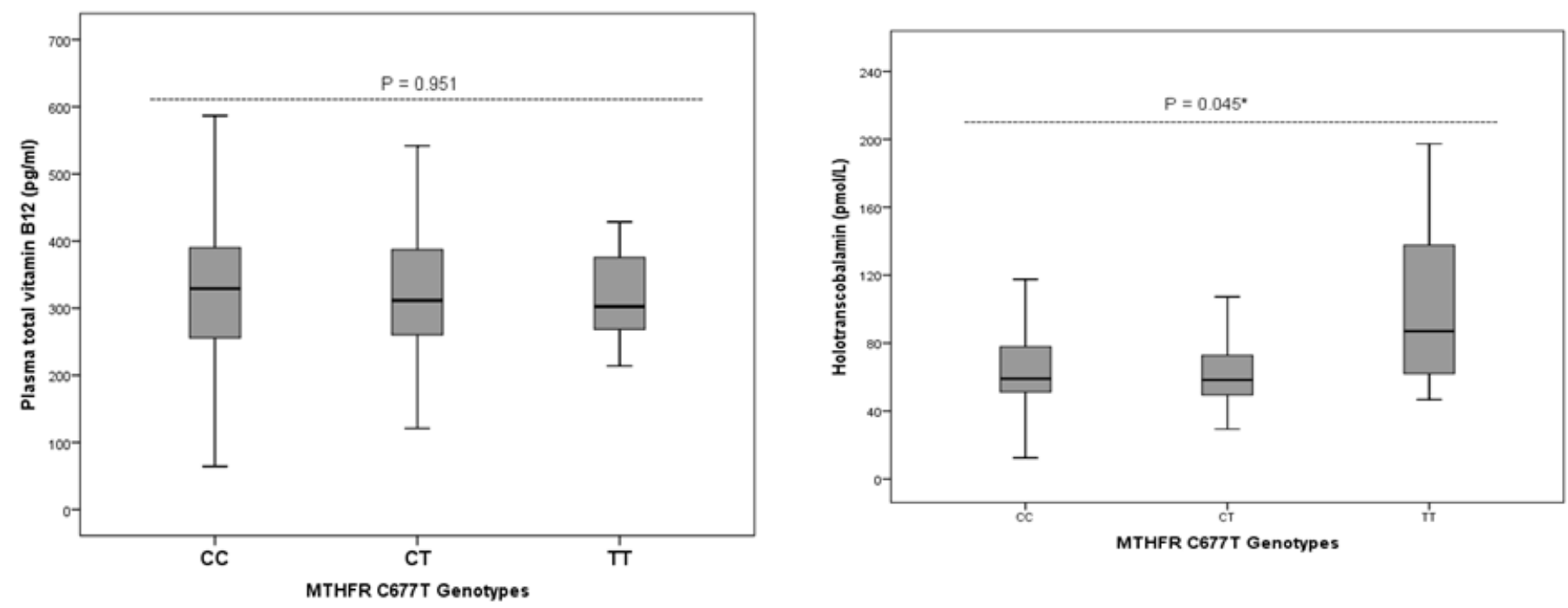

\section{Figure 1}

Association of MTHFR C677T genotypes with the plasma levels of total vitamin B12 and holotranscobalamin in postpartum women * Statistically significant $\mathrm{P}<0.05$ using Kruskal - Wallis $\mathrm{H}$ test; the box-plot represents inter quartile range with middle line representing the median values
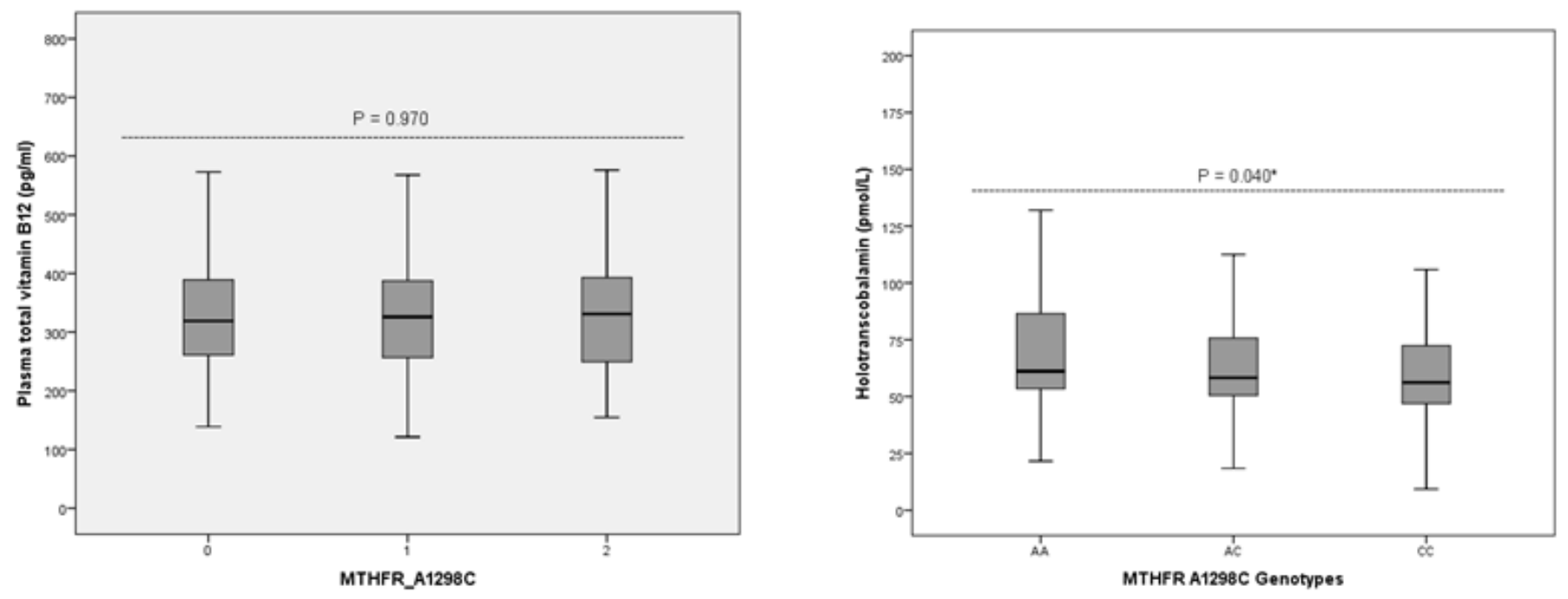


\section{Figure 2}

Association of MTHFR A1298C genotypes with the plasma levels of total vitamin B12 and holotranscobalamin in postpartum women * Statistically significant $\mathrm{P}<0.05$ using Kruskal - Wallis $\mathrm{H}$ test; the box-plot represents inter quartile range with middle line representing the median values 